\title{
TWO-YEARS REVIEW OF PEADIATRIC CPR DATA IN PICU LJUBLJANA - IS THERE ROOM FOR IMPROVEMENT?
}

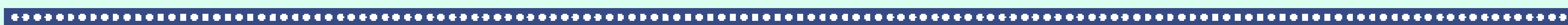

\section{Maja Pajek¹, Mojca Grošelj-Grenc²}

${ }^{1}$ Department of Paediatric Surgery and Intensive Care, Divison of Surgery, University Medical Centre Ljubljana,

Bohoričeva 20, 1000 Ljubljana.

2 Vitasan d.o.o., Podlipovica 43, 1411 Izlake

\section{PURPOSE}

- To evaluate:

- data about cardiopulmonary resuscitation (CPR) in Paediatric Intensive Care Unit (PICU) Ljubljana,

- data about CPR in survivors of intra- and out-ofhospital cardiac arrest, who were admitted to PICU.

\section{METHODS}

- Retrospective analysis of the electronic and paper documentation of children admitted to PICU in the years 2017 and 2018.

- The evaluation was performed in the view of preparation for introduction of the new uniform paediatric Utstein style based electronic report of CPR events in our hospital.

\section{RESULTS}

- 915 children were admitted to the PICU, 31 (3.4\%) needed CPR.

- The average age of resuscitated children was 26.8 ( \pm 42.1$)$ months.

- CPR location:

- PICU (45\%),

- the operating theatre $(13 \%)$,

- other hospital departments $(7 \%)$,

- other hospitals $(19 \%)$,

- out-of-hospital (16\%).

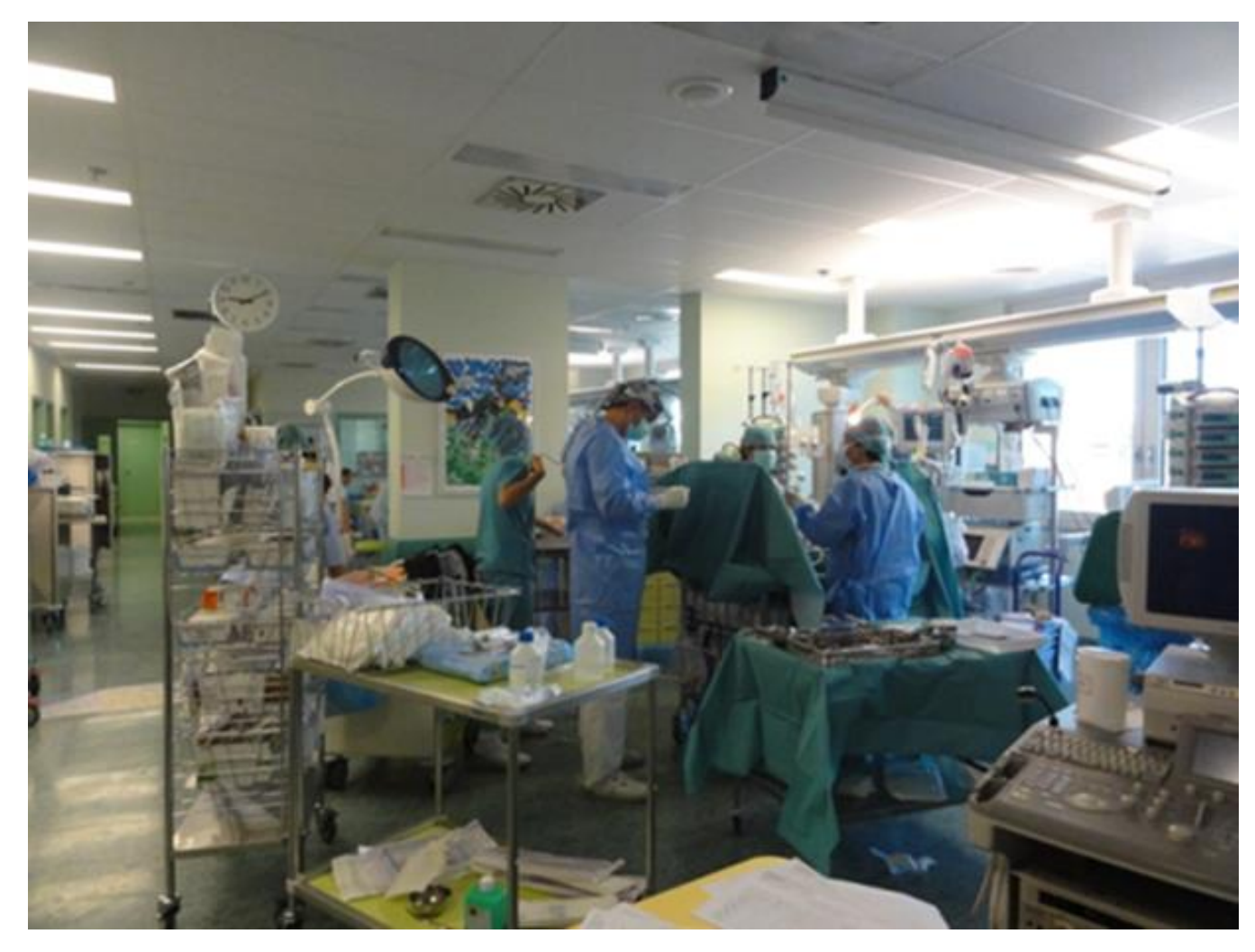

- PICU cardiac arrests most commonly occurred during the winter (36\%), and surprisingly, $21 \%$ in the short period during the changing of shifts (half an hour three-times per day).

- The most common cause of cardiac arrest was circulatory failure (58\%), followed by respiratory failure $(39 \%)$, and trauma (3\%). The mean resuscitation time was $23.7( \pm 32.4)$ minutes.

- The most common cardiac arrest rhythm was terminal bradycardia (55\%), followed by asystole (29\%), PEA (6.5\%), and VF (6.5\%).

- ROSC was achieved in $\mathbf{7 1 \%}$. 64\% of children survived until PICU discharge. Neurological outcome was favourable in $56 \%$ of them.
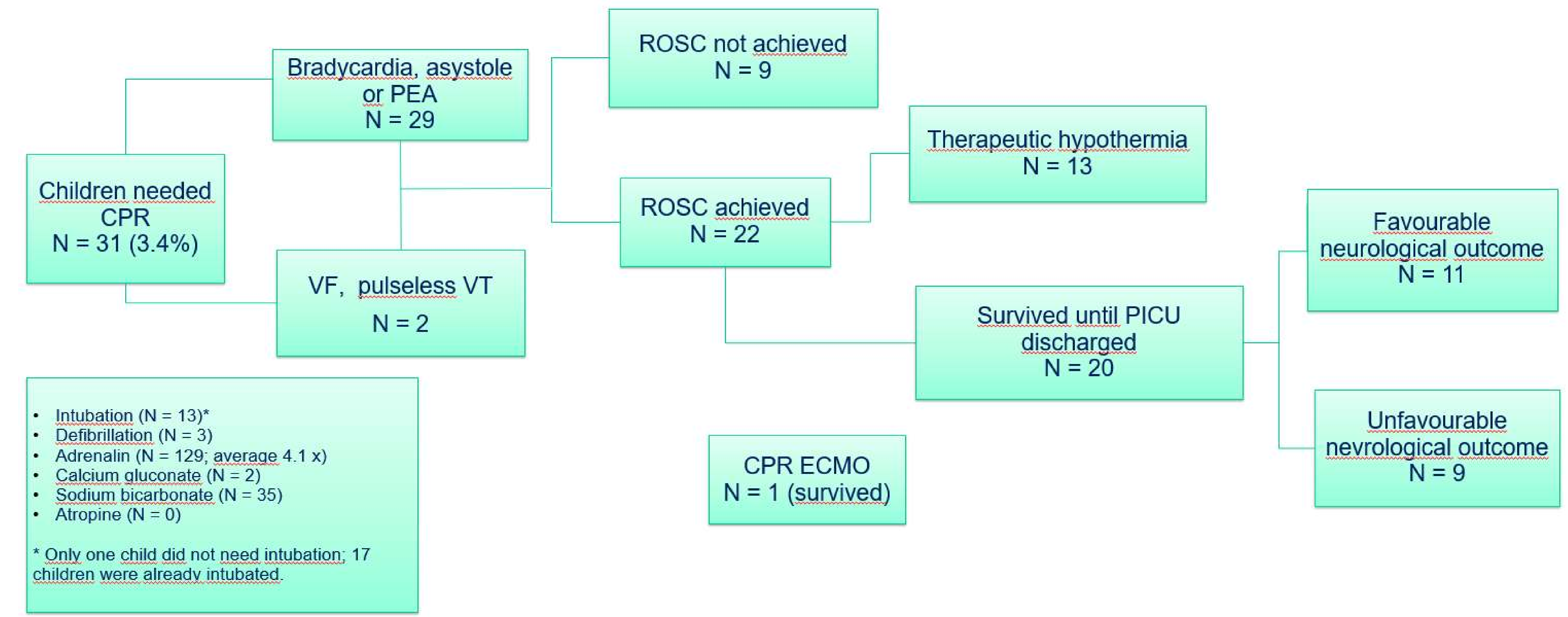

\section{CONCLUSIONS}

- The lack of standardized form in reporting pediatric CPR in our country, which we have noticed during the research, should be addressed in the future, together with introducing the new electronic report of CPR events at our institution.

- High level of CPR events during some particular periods in PICU (winter, shift changing time) should be addressed as well. 